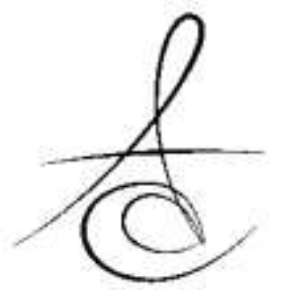

\section{FARKLI İÇECEKLER İLE RENKLENDİRİLMİŞ REZİN NANO SERAMİKLER VE NANO HİBRİT KOMPOZİT REZİNLERİN RENK STABİLİTESİNE BEYAZLATICI AĞIZ GARGARALARININ ETKİSI}

\section{THE EFFECT OF WHITENING MOUTH RINSE ON THE COLOR STABILITY OF RESIN NANO CERAMIC AND NANO HYBRID COMPOSITE STAINED WITH COLORED BEVERAGES}

\author{
Dr. Dt. Işıl Damla ŞENER YAMANER*
}

Işıl Damla Şener Yamaner: ORCID ID: 0000-0002-4790-6542

Makale Kodu/Article code: 4110

Makale Gönderilme tarihi: 18.06.2019

Kabul Tarihi: 28.10.2019

DOI : $10.17567 /$ ataunidfd.638990

\title{
Öz
}

Amaç: Bu çalş̧manın amacı CAD/CAM rezin nano seramik (Lava Ultimate; 3M ESPE) ve nano hibrit kompozit rezin (Grandio/VOCO) materyallerin uzun süre renklendirici içeceklere maruz kalmalarının ve sonrasında 24 ve 72 saatlik beyazlatıcı ağız gargarası uygulanmasının renk stabilitesi üzerine etkisininin vitro olarak değerlendirilmesidir.

Materyal ve Metod: Bu çalışmada CAD/CAM yöntemi ile üretilen 20 adet RNC (Lava Ultimate; 3M ESPE) ve 20 adet nano hibrit kompozit rezin (Grandio/VOCO) numune kullanıldı. Tüm numuneler $(n=40)$ önce 12 gün enerji içeceğinde, sonrasında da yine 12 gün çayda olmak üzere iki farklı renklendirici içecekte bekletildi. Renklendirme işlemi sonrasında numunelerin tümü Listerine Advanced White (Johnson\&Johnson, İngiltere) beyazlatıcı ağız bakım gargarasında bekletilerek beyazlatma işlemine tabii tutuldu. Başlangıç, renklendirme isslemi sonrasında ve beyazlatma isslemi sonrasında 24 ve 72 saat sonra numunelerin renk ölçümleri Vita Easyshade ${ }^{\circledR} \mathbf{V}$ spektrofotometre (Vita Easyshade ${ }^{\circledR}$ V, Vita Zahnfabrik, Bad Sackingen, Almanya) kullanılarak yapıldı. RNC (Lava Ultimate; 3M ESPE) ve nano hibrit kompozit rezin (Grandio/VOCO) numunelerin renklendirme işlemi öncesi ve sonrası arasındaki renk farklılıkları $(\Delta \mathrm{E})$ ile beyazlatma işlemi öncesi ve 24 ile 72 saat sonrası arasındaki renk farklılıkları CIELAB $\triangle \mathrm{E}$ formülü kullanılarak hesaplandı. İstatistiksel analizler tek yönlü varyans analizi (one-way ANOVA) ile yapıldı. $(p=0,05)$

Bulgular: Renklendirme sonrası; RNC (Lava Ultimate; 3M ESPE) numunelerin ortalama $\triangle E$ değeri klinik olarak kabul edilebilir sınırlar içerisinde hesaplanırken nano hibrit kompozit (Grandio/VOCO) numunelerin ortalama $\Delta \mathrm{E}$ değeri klinik olarak kabul edilebilir sınırların üzerinde yer almaktadır. Her iki grubun ortalama $\Delta \mathrm{E}$ değerleri karşılaştırılığında ise istatistiksel olarak anlamlı farklılık bulunmuştur $(p \leq 0,05)$. Her iki grubun ortalama $\Delta E$ değerlerinde 24 ve 72 saat beyazlatıcı ağız gargarasında bekleme sonrasında da istatistiksel olarak anlamlı bir düşüş görülmüştür $(p \leq 0,05)$.

Sonuç: Nano-hibrit kompozit rezin (Grandio/VOCO), RNC (Lava Ultimate; 3M ESPE) 'e göre klinik olarak kabul edilemez düzeyde renklenmektedir. 24 ve 72 saatlik beyazlatıcı ağız gargarası içerisinde bekletilmesi sonucunda her iki malzemede de istatistiksel olarak $(\Delta \mathrm{E})$ değerlerinde anlamlı düşüş bulunmuştur. Bu sonuç beyazlatıcı ağız gargarasının nano hibrit kompozit rezin (Grandio/VOCO) ve RNC (Lava Ultimate; 3M ESPE) malzemelerinde etkin bir beyazlatma sağladığını göstermektedir.

Anahtar Kelimeler: Nano Hibrit Kompozit, Rezin Nano Seramik, Renk, Beyazlatıcı Solüsyon

\section{ABSTRACT}

Aim: The aim of this study was to determine the effect of application of whitening mouth rinse for $24 \mathrm{~h}$ and $72 \mathrm{~h}$ on the color stability of CAD/CAM resin nano ceramic (Lava Ultimate; 3M ESPE) and nano hybrid composite resin (Grandio/VOCO) that stained with colored beverages in vitro.

Material and Methods: RNC (Lava Ultimate; 3M ESPE) $(n=20)$ and nano hybrid composite (Grandio/VOCO) $(n=20)$ were prepared. All specimens were immersed in energy drink for 12 days and tea for 12 days again. After staining procedure the stained specimens were immersed in Listerine Advanced White (Johnson\&Johnson, UK) whitening mouth rinse. İnitially, after staining procedure and two times after bleaching procedure first 24hours later than 72 hours later, the color was measured with Vita Easyshade ${ }^{\circledR} \mathbf{V}$ spektrofotometer. The color difference before and after staining and after 24 hours and 72 hours bleaching was evaluated by CIELAB $\triangle E$ formula. The data were analyzed with one-way ANOVA $(p=0,05)$.

Results: After staining; the calculated avarage $\triangle E$ value of RNC (Lava Ultimate; 3M ESPE) samples' was clinically acceptable but the calculated avarage $\Delta \mathrm{E}$ value of the nano hybrid composite (Grandio/VOCO) samples' was above the acceptable level. When the avarage $\Delta E$ values of the groups were compared the difference was statistically significant $(p \leq 0,05)$. When the avarage $\Delta \mathrm{E}$ values of the groups were compared after bleaching with the mouth rinse for 24 and 72 hours, decrease in $\Delta \mathrm{E}$ values was statistically significant $(p \leq 0,05)$.

Conclusion: Nano hybrid composite resins (Grandio/VOCO) were stained above the clinical acceptance level. After bleaching with the mouth rinse for 24 and 72 hours, $\Delta \mathrm{E}$ values was statistically significantly decreased that means that whitening mouth rinse effectively bleached both RNC (Lava Ultimate; 3M ESPE) and nano hybrid composite (Grandio/VOCO).

Key words: Nano Hybrıd Composite, Resin Nano Ceramic, Color stability, Whitening Mouth Rinse

* Özel Poliklinik, DMR DENT Ağız ve Diș Sağığı Polikliniği, İstanbul, Türkiye

Kaynakça Bilgisi: Şener Yamaner ID.Farklı İçecekler ile Renklendirilmiş Rezin Nano Seramikler Ve Nano Hibrit Kompozit Rezinlerin Renk Stabilitesine Beyazlatıcı Ağız Gargaralarının Etkisi. Atatürk Üniv Diş Hek Fak Derg 2020; 30: 93-100.

Citation Information: Sener Yamaner ID. The Effect of Whitening Mouth Rinse on the Color Stability of Resin Nano Ceramic and Nano Hybrid Composite Stained With Colored Beverages. J Dent Fac Atatürk Uni 2020; 30: 93-100. 


\section{GİRİş}

Son dönemde bilgisayar destekli dizayn ve bilgisayar destekli üretim (CAD/CAM) yöntemi dental restorasyonların hazırlanmasında ağırlıklı olarak kullanılmaktadır. ${ }^{1,2}$ CAD/CAM yöntemiyle üretilen restorasyonlar için kullanıma uygun; seramik bloklar, kompozit bloklar (geçici ve daimi restorasyonlar için) ve en yeni üretilen rezin nano seramik (Resin Nano Ceramic (RNC)) bloklar, restoratif malzeme çeşitliliğini arttırmaktadır. ${ }^{1,3}$ RNC blokların üretimi ile direkt kompozit rezinlere göre mekanik özelliklerin geliştirilmesini sağlayan post polimerizasyon metodları kullanılabilmektedir ${ }^{4,5}$ Ayrıca RNC malzemenin yapısı sayesinde, uygulanabilme kolaylığı ile birlikte bitimin cilalı yüzey olarak hazırlanabilmesi avantajları da mevcuttur. ${ }^{1}$

Lava Ultimate RNC (Lava Ultimate, 3M ESPE, St. Paul, USA), CAD/CAM yöntemiyle üretilen seramik bloklara alternatif olarak geliştirilmiş rezin ve seramik karışımı kompozit malzemedir. RNC (Lava Ultimate; 3M ESPE), kompozit rezin benzeri yüksek kırılma direnci nedeniyle kırılgan değilken, cam seramik benzeri uzun dönem estetiği sağlayabilen mükemmel cila retansiyonuna sahiptir. ${ }^{6,7}$

Restoratif bir malzemenin klinik başarısını ve ömrünü belirleyici en önemli parametreler ağız içerisinde bütünlüğünü ve rengini uzun dönem koruyabilmesidir. RNC (Lava Ultimate; 3M ESPE), CAD/CAM restoratif malzemelerin renklenmesi konusunda elde edilmiş veriler sınırlıdır. 6,8

Günümüzde CAD/CAM yöntemiyle üretilen malzemelerin çeşitliliği artarken diğer taraftan direkt kompozit rezinlerde geliştirilmektedir. Ancak rezin malzemenin matriks yapısı sebebiyle en yeni üretilen rezinler bile sıvı absorbe etmeye devam etmektedirler. Kahve, çay, kırmızı şarap, klorheksidin veya beyazlatıcı ajanlar içeren çeşitli sıvılara uzun süre maruz kaldığında boyar maddelerin penetrasyonu kaçınılmazdır. ${ }^{9}$ Kompozit rezinlerin yenilenmelerinin en önemli sebeplerinden biri olan renklenmeler; renklendirici ajanların adsorpsiyonu veya kompozitin yüzeyinin aşınması, çözünmesi sonucunda meydana gelir. ${ }^{10}$ Renklenme miktarı; malzenin matriksinde meydana gelen kimyasal reaksiyonlar, doldurucu partikül boyutu ve miktarı, polimerizasyon derecesi, su emilimi, renklendiricilerle beslenme, ağız hijyeni ve restorasyonun yüzey pürüzlülüğü gibi çeşitli faktörlere bağlıdır. ${ }^{11,12}$

Kompozit rezin malzemenin renk stabilitesi ve optimum bütünlük sağlayabilmesi için yeni tip doldurucu kullanımı ve matrix değişiklikleri ile fiziksel ve estetik özellikleri geliştirilmektedir. ${ }^{13-15}$ Nano doldurucular ve nano kümelerin kullanıldığı kompozit rezinler üretilmektedir. Nanokompozitler olarak isimlendirilen, 0,1-100 nm boyutlarında inorganik doldurucular ile üretilen bu kompozitler, hibrit kompozit rezinlerin mekanik özellikleri ile mikrofil kompozit rezinlerin polisaj kalıcılığını sağlamaktadır. ${ }^{16}$

Nano hibrit kompozit rezin Grandio/VOCO da, nano doldurucular sayesinde $\% 87$ doldurucu içeriği ve $\% 1,57$ polimerizasyon büzülme miktarı sağlanabilmiştir. Bu sayede nano partiküller, matriks içerisinde ağ etkisi göstererek abrazyon ve gerilme direncini arttırır. ${ }^{17,18}$

RNC ve kompozit rezin malzemelerin renklenmesi; maruz kaldığı renklendirici solusyonun tipi ile maruz kalma süresine ve malzemenin içeriği ile yapısına bağlıdır. ${ }^{17,18}$

Günümüzde renk ölçümü; görsel olarak veya kolorimetre, spektroradyometre, spektrofotometre ve dijital kamera-görüntüleme sistemleri gibi cihazlar yardımıyla yapılmaktadır. ${ }^{19}$

Malzemelerin renk parametrelerinin belirlenmesinde; Munsell ve Uluslararası Aydınlatma Komisyonu (Commission Internationale de I'Eclairage Lab (CIE L*a*b*)) CIELAB renk sistemleri, uluslararası kabul edilebilirliği, güvenilirliği ve pratik kullanımları açısından kabul edilmiş sistemlerdir. ${ }^{20}$

Çok sayıda farklı, renk farkı $(\Delta \mathrm{E})$ formülü mevcuttur ancak dental araştırmalarda çoğunlukla CIELAB $\Delta \mathrm{E}$ formülü kullanılmaktadır. ${ }^{21}$ Renk farkı $(\Delta \mathrm{E})$ değeri rengin klinik olarak kabul edilebilirliğini belirler. 22,23 $\mathrm{O}^{\prime}$ Brien ve ark. ${ }^{24} \Delta \mathrm{E}$ değerlerini sınıflamışlardır. Yapılan ölçümler sonunda $\Delta \mathrm{E}=0$ ise malzeme renk açısından stabil olarak kabul edilir. Renk farkı değeri 0,5 $\leq \Delta \mathrm{E} \leq$ 1 ise fark klinik olarak algılanamaz. Renk farkı değeri 1 $\leq \Delta \mathrm{E} \leq 2$ ise fark klinik olarak algılanabilir ve $\Delta \mathrm{E}>3,7$ ise renk farkı klinik olarak kabul edilemez olarak değerlendirilmiştir.

Dental estetik kavramının insan hayatındaki öneminin artışı, üreticileri ve araştırmacıları yeni beyazlatma ürünlerini geliştirmeye yöneltmiştir. Bu nedenle kısa sürede daha beyaz dişlere sahip olunacağı iddiası ile çok sayıda beyazlatıcı ağız gargarası üretilmektedir. Uygulanımının kolay oluşu ve düşük maliyeti beyazlatıcı ağız gargarası kullanımının avantajlarıdır. ${ }^{25} \mathrm{Bu}$ ajanların hem diş dokusuna hem de ağız içerisinde kullanılan restoratif malzemelere olan beyazlatıcı etkisi çok sayıda çalışmada incelenmiştir. ${ }^{25}$ Ancak dental markete yeni sunulan RNC (Lava Ultimate; 3M ESPE) ve nano hibrit kompozit rezinlere (Grandio/VOCO) 
etkisi konusunda elde edilmiş veriler sınırlıdır.

$\mathrm{Bu}$ çalışmanın amacı, CAD/CAM rezin nano seramik (Lava Ultimate; 3M ESPE) ve nano hibrit kompozit rezin (Grandio/VOCO) materyallerin uzun süre renklendirici içeceklere maruz kalmalarının öncesi ve sonrasında 24 ve 72 saatlik beyazlatıcı ağız gargarası uygulanmasının etkisinin in vitro olarak değerlendirmektir. Çalışma öncesi hipotezler; a) Nano hibrit kompozit rezinlerin CAD/CAM rezin nano seramiklere göre renklendirici içeceklerle daha fazla renkleneceği ve b) beyazlatıcı ağız gargarasının nano hibrit kompozit rezinlerde daha etkili olacağıdır.

\section{MATERYAL VE METOD}

$\mathrm{Bu}$ çalışmada CAD/CAM yöntemi ile üretilen RNC (Lava Ultimate; 3M ESPE) ile $1 \mathrm{~nm}$ cam seramik ve $20-50 \mathrm{~nm}$ boyutlarında silisyum dioksit partikülleri içeren nano hibrit kompozit rezin (Grandio/VOCO) kullanılmıştır . Çalışmada kullanılan malzemelerin tipi, üretici firma adı ve kompozisyonları Tablo 1 de gösterilmektedir.

Tablo 1. Çalışmada kullanılan malzemelerin tipi, üretici firma adı ve kompozisyonları

\begin{tabular}{|c|c|c|c|}
\hline Ürün adı & Tipi & $\begin{array}{l}\text { Üretici } \\
\text { firma }\end{array}$ & Kompozisyon \\
\hline $\begin{array}{l}\text { Lava } \\
\text { Ultimate }\end{array}$ & $\mid \begin{array}{c}\text { Rezin Nano } \\
\text { Seramik }\end{array}$ & $\begin{array}{l}\text { 3M ESPE, } \\
\text { Almanya }\end{array}$ & $\begin{array}{c}\text { Bis-GMA, Bis-EMA, UDMA, } \\
\text { TEGDMA } \\
\text { Doldurucu oranı ağırlık olarak } \\
\% 80 \\
\mathrm{ZrO}_{2} / \mathrm{SiO}_{2} \text { kümeleri } \\
\mathrm{SiO}_{2}(20 \mathrm{~nm}) \text { ve } \mathrm{ZrO}_{2}(4-11 \mathrm{~nm})\end{array}$ \\
\hline Grandio & $\begin{array}{c}\text { Nano-Hibrit } \\
\text { kompozit } \\
\text { rezin }\end{array}$ & $\begin{array}{c}\text { Voco, } \\
\text { Cuxhaven } \\
\text {, Almanya }\end{array}$ & $\begin{array}{c}\text { Bis-GMA, TEGDMA, } \\
\text { Baryum boron alumino silikat } \\
\text { cam }(0,1-2,5 \mu \mathrm{m}) \text {, silika }(20-60 \\
\mathrm{nm}) \text {. Doldurucu oranı ağırlık } \\
\text { olarak } \% 87\end{array}$ \\
\hline $\begin{array}{l}\text { Listerine } \\
\text { Advanced } \\
\text { White }\end{array}$ & & $\begin{array}{l}\text { Johnson\& } \\
\text { Johnson, } \\
\text { İngiltere }\end{array}$ & $\begin{array}{c}\text { Aqua, Alkol, Sorbitol, } \\
\text { Tetrapotasyum Profosfat, } \\
\text { Pentasodyum Trifosfat, Sitrik } \\
\text { asit, poloxamer 407, Sodyum } \\
\text { Benzoat, Eucalyptol, Timol, } \\
\text { Mentol, sodium sakkarin, } \\
\text { Sodyum florid, Tetrasodyum } \\
\text { Pyrofosfat, Propilen } \\
\text { glikol,Sucralose, aroma, } \\
\text { Disodyum fosfat, Sodyum florür. }\end{array}$ \\
\hline
\end{tabular}

\section{Nano hibrit kompozit numune hazırlanması}

Politetrafloroetilen kalıplar kullanılarak, 2mm kalınlık ve $8 \mathrm{~mm}$ çapa sahip 20 adet nano hibrit kompozit rezin (Grandio/VOCO) numune hazırlandı. Nano hibrit kompozit rezin, kalıp içerisine yerleştirildikten sonra, yüzeyin düzgün olması amacıyla her iki yüzeyinde mikroskop camı varlığında polimerizasyon cihazı ile (Bluephase, Ivoclar, Vivadent, Schaan, Liechtenstein; Işık çıkışı: $1200 \mathrm{mw} / \mathrm{cm}^{2}$ ) üretici firma talimatları doğrultusunda 40 saniye süre ile polimerize edildi $(n=20)$.

Politetrafloroetilen kalıplardan çıkartılan tüm numuneler polimerizasyonun tamamlanması amacıyla $37^{\circ} \mathrm{C}$ distile suda 24 saat süre ile bekletildi. ${ }^{26}$ Hazırlanan kompozit numuneler sırasıyla grenleri kalından inceye doğru değişen polisaj diskleri (Sof-Lex, 3 M ESPE) ile su soğutması altında cilalandı. ${ }^{27}$

Rezin nano seramik numune hazırlanması

Lava Ultimate (Lava Ultimate; 3M ESPE) RNC bloklar kesitlendirme cihazına (IsoMet; Buehler Ltd., Easton Illinois, ABD) sabitlendi. 20 adet RNC numune (1,5 mm uzunluk $x 1,5 \mathrm{~mm}$ genişlik $\times 2 \mathrm{~mm}$ yükseklik) su soğutması altında elmas bıçak (Buehler Diamond Wafering Blade, Series 15 LC, Buehler,ABD) kullanılarak hazır RNC bloklardan (Lava Ultimate, 3M ESPE) kesilerek hazırlandı. Numuneler mekanik olarak cila seti (Kit 4477, Qpolishing Sistemi, Komet, Lemgo, Almanya) ile cilalandı.

Tüm numunelerin başlangıç renk ölçümleri spektrofotometre (Vita Easyshade ${ }^{\circledR}$ V, Vita Zahnfabrik, Bad Sackingen, Almanya) kullanılarak standart günışığı (CIE standard illuminant D65) aydınlatma koşullarında $^{28}$ her numuneden yapılan üç ölçümün ortalama değeri alınarak, Commision Internationale de I'Eclairage Lab (CIE L*a*b*) değeri olarak kaydedildi. CIE-Lab sistemine göre doğadaki tüm renkler kırmızı, mavi ve yeşil renklerinin karışımından oluşur. L*değeri açıklık veya koyuluğu belirlerken, a* değeri kırmızıı̆ı (pozitif $a^{*}$ ) veya yeşilliği (negatif $a^{*}$ ), b* değeri ise sarılığı (pozitif $b^{*}$ ) veya maviliği (negatif $b^{*}$ ) ölçer. 29,30

\section{Renklendirme ve beyazlatma işlemi}

Başlangıç ölçümleri sonrasında tüm numuneler sırasıyla, enerji içeceği (Red Bull ${ }^{\circledR}$, RED BULL GmbH, Avusturya) ve çay (Twinings earl grey, Londra, İngiltere; üretici firma talimatları doğrultusunda 150 $\mathrm{ml}$ kaynayan suya $5 \mathrm{~g}$ çay eklenerek hazırlanmıştır.) içerisinde bekletilerek renklendirme işlemine tabii tutuldu.

Önceki çalışmalarda ${ }^{31,32}$ renklendirici solusyonda bekletilme süresi kahve ile standardize edilmiştir. Günde ortalama 3,2 bardak kahve içildiği, 1 bardak kahvenin 15 dak.da tüketilmesi sebebiyle günlük renklendirici içeceğe maruz kalma süresinin 48 dakika olduğu, aylık olarak ise bu sürenin 1440 dakika (24 saat;1 gün) olduğu tespit edilmiştir. Bundan dolayı numunelerin 12 günlük renklendirici solusyonda bekle- 
tilmeleri ağız içerisindeki 1 yıllık kullanıma denk olduğu belirtilmiştir. Solüsyon içerisinde bekletilme süresi tüm renklendirici içecekler için standardize edilmiştir. Bu çalışmada da tüm numuneler $(n=40)$ önce 12 gün enerji içeceğinde, sonrasında da yine 12 gün çayda olmak üzere iki farklı renklendirici içecekte bekletilmiştir. Renklendirici içecekler her gün yenilenmiştir.

Numuneler, 24 günlük renklenme süresi sonunda beş dakika süreyle distile suyla yıkanıp renk ölçümü öncesinde kağıtla kurutuldu. Renklendirme işlemi sonrasında numunelerin renk ölçümleri daha önce bahsedilen spektrofotometre ile yapıldı.

Ölçüm sonrasında renklenmiş numunelerin tümü Listerine Advanced White (Johnson\&Johnson, İngiltere) beyazlatıcı ağız bakım gargarasında bekletilerek beyazlatma işlemine tabii tutuldu.

RNC (Lava Ultimate; 3M ESPE) ve nano hibrit kompozit rezin (Grandio/VOCO) numunelerin renklendirme işlemi öncesi ve sonrası arasındaki renk farklılıkları $(\Delta \mathrm{E})$ ile beyazlatma işlemi öncesi ve 24 ile 72 saat sonrası arasındaki renk farklılıkları $(\Delta \mathrm{E})$ aşağıdaki

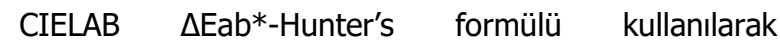
hesaplandı.

$$
\begin{aligned}
& \Delta \mathrm{E}=\left[(\Delta \mathrm{L})^{2}+(\Delta \mathrm{a})^{2}+(\Delta \mathrm{b})^{2}\right]^{1 / 2} \quad(25,29,30) \\
& \text { İstatistiksel Değerlendirme }
\end{aligned}
$$

$\mathrm{Bu}$ çalışmada elde edilen verilerin istatistiksel analizleri için SPSS istatistik programı (Version 15.0, SPSS Inc., Chicago,Illinois, ABD) kullanıldı. Çalışma verileri değerlendirilirken iki grup arasındaki değişkenliğin zamana bağlı değerlendirilmesinde tekrarlanabilir varyans analizi kullanıldı. İki grup arasındaki zamana bağlı olmaksızın yapılan değerlendirilmelerde ise Tek yönlü varyans analizi (one-way ANOVA) kullanıldı. Sonuçlar, $p \leq 0,05$ anlamlılık düzeyinde değerlendirildi (Tablo 2).

Tablo 2. Gruplara ait varyans analizi sonuçları.

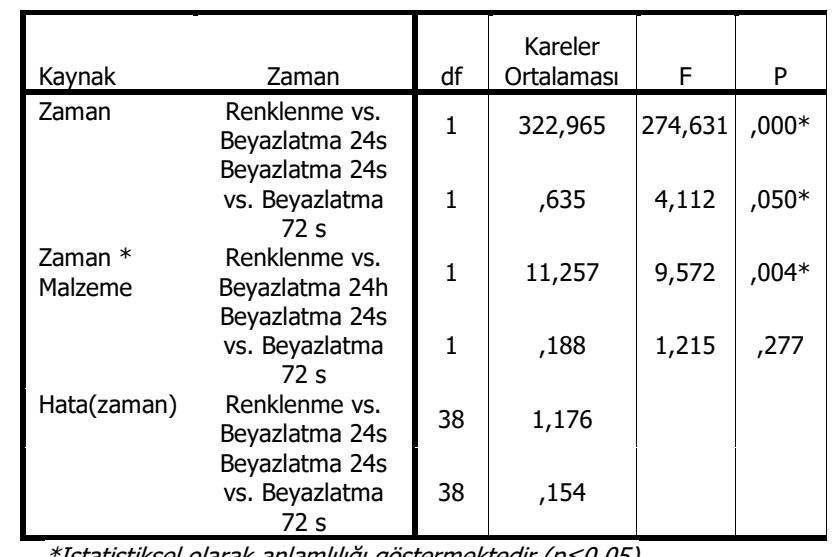

*Istatistiksel olarak anlamlıl̆ğ göstermektedir. $(p \leq 0,05)$

\section{BULGULAR}

Çalışmamızda RNC (Lava Ultimate; 3M ESPE) ve nano hibrit kompozit rezin (Grandio/VOCO) numunelerin renklendirme sonrasındaki $\Delta \mathrm{E}$ değeri 3,7 den büyük ise insan gözü ile algılanabilir renk farkı oluştuğundan klinik olarak kabul edilemez olarak değerlendirilmiştir. ${ }^{24}$

RNC (Lava Ultimate; 3M ESPE) numune grubunun renklenme sonrası ölçülen 2,34 ile 4,35 arası değişen $\Delta \mathrm{E}$ değerleri ortalama $3,7 \pm 0,55$ iken nano hibrit kompozit rezin (Grandio/VOCO) numune grubunun 2,69 ile 8,78 arası değişen ortalama $\Delta \mathrm{E}$ değeri $5,27 \pm$ 1,39 olarak hesaplanmıştır.

RNC (Lava Ultimate; 3M ESPE) numune grubunun ilk 24 saat beyazlatma sonrası 0,41 ile 2,28 arası değişen $\Delta \mathrm{E}$ değerleri ortalama $1,39 \pm 0,47$ iken 72 saat beyazlatma sonrası 0,22 ile 2,35 arası değişen ortalama $\Delta \mathrm{E}$ değeri $1,19 \pm 0,51$ olarak hesaplanmıştır. Buna karşlık nano hibrit kompozit rezin (Grandio/ VOCO) numune grubunun ilk 24 saat beyazlatma sonrası 0,24 ile 3,41 arası değişen $\Delta \mathrm{E}$ değerleri ortalama $1,89 \pm 0,94$ iken 72 saat beyazlatma sonrası 0,33 ile 3,25 arası değişen ortalama $\Delta \mathrm{E}$ değeri $1,84 \pm$ 0,98 olarak hesaplanmıştır.

\section{A-Renklenme}

Renklendirme sonrası RNC (Lava Ultimate; 3M ESPE) numunelerin ortalama $\Delta \mathrm{E}$ değeri 3,73,7 $\pm 0,55$ olarak bulunmuştur. Bu değer klinik olarak kabul edlebilir sınırlar içerisinde yer almaktadır. Buna karşılık nano hibrit kompozit (Grandio/VOCO) numunelerin ortalama $\Delta \mathrm{E}$ değeri $5,27 \pm 1,39$ olarak bulunmuştur. $\mathrm{Bu}$ değer ise klinik olarak kabul edilebilir sınırların üzerinde yer almaktadır. Her iki grubun ortalama $\Delta \mathrm{E}$ değerleri karşılaştırıldığında renklendirme sonrası istatistiksel olarak anlamlı farklılık bulunmuştur $(p \leq 0,05)$. (Grafik 1)

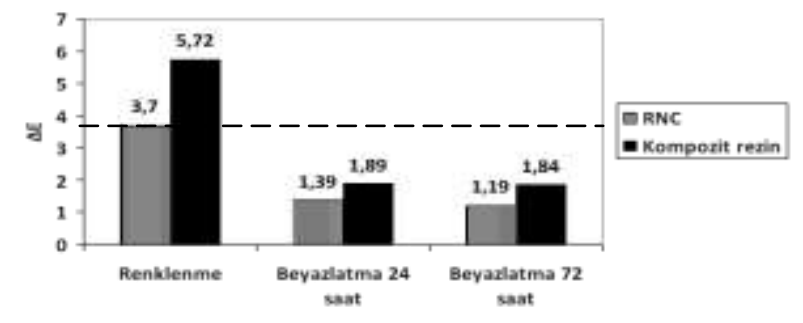

Grafik 1. RNC ve nano hibrit kompozit rezin gruplarının renklendirme ve beyazlatma işlemleri sonrası ortalama $\Delta \mathrm{E}$ değerleri 


\section{B-Beyazlatma}

24 saat beyazlatıcı ağız gargarasında bekleme sonrasında nano hibrit kompozit (Grandio/VOCO) numunelerdeki ortalama $\Delta \mathrm{E}$ değeri $1,89 \pm 0,94$ olarak hesaplanırken RNC (Lava Ultimate; 3M ESPE) numunelerindeki ortalama $\Delta \mathrm{E}$ değeri $1,39 \pm 0,47$ olarak bulunmuştur. Her iki grubun ortalama $\Delta \mathrm{E}$ değerlerinde de 24 saat beyazlatıcı ağız gargarasında bekleme sonrasında istatistiksel olarak anlamlı bir düşüş görülmüştür. 72 saat beyazlatıcı ağız gargarasında bekleme sonrasında nano hibrit kompozit (Grandio/VOCO) numunelerdeki ortalama $\Delta \mathrm{E}$ değeri $1,84 \pm 0,98$ olarak hesaplanırken RNC (Lava Ultimate; 3M ESPE) numunelerindeki ortalama $\Delta \mathrm{E}$ değeri $1,19 \pm 0,51$ olarak bulunmuştur. Aynı şekilde her iki grubun ortalama $\Delta \mathrm{E}$ değerlerinde de 72 saat beyazlatıcı ağız gargarasında bekleme sonrasında istatistiksel olarak anlamlı bir düşüş görülmüştür $(p \leq 0,05)$. (Grafik 1$)$

\section{C-Malzeme}

Renklenmiş RNC (Lava Ultimate; 3M ESPE) ve nano hibrit kompozit (Grandio/VOCO) numunelerin 24 saat beyazlatıcı ağız gargarasında bekleme sonrasında ortalama $\Delta \mathrm{E}$ değerlerindeki düşüş farkı istatistiksel olarak anlamlı bulunmuştur( $(\mathrm{p} \leq 0,05)$. Buna karşılık 72 saat beyazlatıcı ağız gargarasında bekleme sonrasında ki ortalama $\Delta \mathrm{E}$ değerlerdeki düşüş farkı istatistiksel olarak anlamlı bulunmamıştır ( $p \geq 0,05)$.

\section{TARTIŞMA}

Renklenme çalışmalarında güvenilir sonuçlar elde edilebilmesi amacıyla numune hazırlanması çalışmanın en önemli safhalardan biridir. Kompozit rezin numunelerin hazırlanması sırasında reaksiyona girmeyen bileşenlerin ortamdan uzaklaştırılması ve ideal polimerizasyonun sağlanması için numunelerin başlangıç renk ölçümü öncesinde numunelerin $37^{\circ} \mathrm{C}$ suda 24 saat bekletilmesi gerekmektedir. Bu çalışmada da nano hibrit kompozit (Grandio/VOCO) numuneler polimerizasyonun tamamlanması amacıyla $37^{\circ} \mathrm{C}$ distile suda 24 saat süre ile bekletildi. ${ }^{33,34}$

Restoratif malzemelerdeki renklenme gözle veya aletli tekniklerle değerlendirilebilir. Ancak rengin algılanmasını etkileyen; ışık şiddetinin yanısıra hekimin cinsiyeti, yaşı, mesleki tecrübesi, kullandığı ilaçlar, renk reseptörlerinin yorgunluğu ve duygu durumu gibi çok sayıda faktör mevcuttur. ${ }^{35}$ Araştırmacıların renk algıları arasındaki farklııklar nedeniyle gözle yapılan değerlendirmeler güvenilir olmayabilirler. ${ }^{36}$ Görsel değerlendirmeler yanıltıc olabilir. ${ }^{37}$

Gözle ve cihazla yapılan renk ölçümü karşılaştırıldığında; sayısal olarak veri elde edilebilmesi, objek- tif, hızlı ve tekrarlanabilir sonuç vermesi gibi özellikleri sebebiyle spektrofotometre ve kolorimetre gibi dijital renk ölçüm cihazları ile yapılan renk ölçümü daha güvenilirdir. ${ }^{37,38}$ Günümüzde kolorimetre, spektroradyometre, spektrofotometre ve dijital kamera ve görüntü analizi sistemleri gibi cihazlar renk değerlendirilmesi işlemi yapılabilmektedir. Spektrofotometre ile yapılan renk farklılık değerlendirmeleri, dental malzeme çalışmalarında en güvenilir teknik olarak tespit edilmiştir. $^{36,39}$

Görsel renk seçiminden kaynaklanan hataların önüne, aletli renk ölçüm cihazları içinde en doğru sonucu veren spektrofotometreler ile geçilebilmektedir. Spektrofotometrenin görsel renk ölçüm yöntemiyle karşılaştırıldığı bir çalışmada, diş renginin spektrofotometre ile 5 kat daha doğru belirlenebildiği bulunmuştur. ${ }^{40}$

Araştırmacılar, spektrofotometreyi, görsel renk ölçüm yöntemiyle karşılaştırmışlar ve istatistiksel olarak spektrofotometrenin daha doğru sonuç verdiğini bulmuşlardır. ${ }^{40-42}$

İnsan gözünün algılayamadığı renk farklılıklarının tespitinde spektrofotometre cihazlarının kullanımı gerekmektedir. Spektrofotometre ile elde edilen $L^{*} a^{*}$, b * değerlerinin tek başına anlamını değerlendirmek oldukça zor iken renk değişimini bildiren $\Delta \mathrm{E}$ değeri daha anlamlıdır. ${ }^{43}$

Johnson ve Kao, ${ }^{10}$ insan gözü ve kalorimetre ile yaptıkları klinik çalışmasında klinik olarak kabul edilebilir renk benzerliğinde ortalama $\Delta \mathrm{E}$ değerinin CIELAB 3,7 olduğunu tespit etmişlerdir. Ruyter ve ark. ${ }^{11}$ ise gözlemcilerin $\% 50$ sinin dental kompozit numune çiftlerinde renk farkı kabul edilemez olduğunda ortalama $\Delta \mathrm{E}$ değerinin CIELAB yaklaşık olarak 3,3 olduğu sonucuna varmışlardır. ${ }^{39,44}$

Bir laboratuvar çalışmasında O'Brien ve ark. ${ }^{45}$ ise CIELAB renk farkı formülünü Munsell parametrelerini baz alan farklı bir renk farkı formülü ile karşılaştırdıklarında $\Delta \mathrm{E}<1$ olduğunda fark mükemmel ve $\Delta \mathrm{E}=2$ ise renk farkının klinik olarak kabul edilebilir olduğunu belirtmişlerdir.

$\mathrm{Bu}$ çalışmada renk ölçümleri spektrofotometre olarak Vita Easyshade V (Vita Easyshade ${ }^{\circledR}$ V, Vita Zahnfabrik, Bad Sackingen, Almanya) kullanılarak yapıldı. Ölçümlerden elde edilen veriler Commision Internationale de I'Eclairage Lab (CIE L*a*b*) değeri olarak kaydedildi. Bu sayede küçük renk farkları $(\Delta \mathrm{E})$ dahi tespit edilebilmiş oldu. Çeşitli çalışmalarda farklı elektronik spektrofotometreler kullanılmış ve spektrofotometrelerin insan gözü ile karşılaştırılması yapılmıştır. ${ }^{46}$ 
Um and Ruyter ${ }^{47}$ çalışmalarında çayın sarı renklendirici içerdiğini ancak çay renklendirmesinin kompozit malzemenin polar renklendiriciyi yüzeysel olarak emmesi nedeniyle oluştuğundan fırçalanarak uzaklaştırılabileceğini açıklamışlardır. Malzemelerin renk stabilitesi için boyar solusyona maruz kalma süresi kritik faktördür. Yannikakis ve ark. ${ }^{43}$ çalışmasında olduğu gibi bu çalışmada da boyar solusyona maruz kalma süresi arttıkça renk değişimi artmıştır.

Arif ve ark. ${ }^{6}$ zirkonya ile güçlendirilmiş lityum silikat seramik, lityum disilikat cam seramik ve RNC (Lava Ultimate) gibi CAD/CAM yöntemi ile üretilen restoratif materyallerin renklendirici içeceğe maruz kaldıklarında renk değişimlerini inceledikleri çalışmasında RNC (Lava Ultimate; 3M ESPE) veneer restorasyonlarda $\Delta \mathrm{E}$ değerinin klinik olarak kabul edilemez olduğunu tespit etmişlerdir.

Yoğun kahve tüketen bireylerde estetik beklentinin yüksek olduğu ön bölge lamina restorasyonlarında RNC (Lava Ultimate; 3M ESPE) kullanımından kaçınılması gerektiği ancak estetiğin öncelikli olmadığı posterior inlay ve onlay restorasyonlarında RNC (Lava Ultimate; 3M ESPE) kullanımının endike olduğu tespit edilmiştir. ${ }^{6}$

Bu çalışmada 1yıllık (12 gün) enerji çeceği ve çay ile renklendirme sonrası RNC (Lava Ultimate; 3M $\mathrm{ESPE}$ ) ortalama $\triangle \mathrm{E}$ değeri 3,7 olarak tespit edilirken, başka bir çalışmada 4 hafta çay ile renklendirilen RNC (Lava Ultimate; 3M ESPE) ortalama $\Delta \mathrm{E}$ değeri 5,8 olarak tespit edilmiştir. ${ }^{48}$ Çalışmalar arasındaki bu farkın numunelerin renklendirici solusyonlardaki bekletilme sürelerinden kaynaklandığı düşünülmektedir.

Kompozit rezinlerin renk stabilitesini; rezinin matriksi, fotobaşlatıcı sistemi ve doldurucu tipi, boyutu ve miktarının belirlediği bilinmektedir. ${ }^{49,50}$ Çalışmalarda kompozit rezinlerin doldurucu oranı yükseldikçe su emilim miktarı ve polimerizasyon büzülmesinin azaldığı ifade edilmektedir. ${ }^{51}$

$\mathrm{Bu}$ çalışmada iki kompozit bazlı materyalin renklenmesi ve beyazlatılması karşılaştırılmıştır. 12 günlük renklendirme süreci sonrasında RNC (Lava Ultimate; 3M ESPE) numunelerin ortalama $\Delta \mathrm{E}$ değeri $(\Delta \mathrm{E}=3,7)$ klinik olarak kabul edilebilir sınırlar içerisinde bulunmuştur. Ancak nano-hibrit kompozit (Grandio/ Voco) numunelerin ortalama $\Delta \mathrm{E}$ değeri $(\Delta \mathrm{E}=5,27 \pm$ $1,39)$ klinik olarak kabul edilebilen eşik $\Delta \mathrm{E}$ değerinden $(\Delta \mathrm{E}=3,7)$ yüksek bulunmuştur. Her iki malzemenin ortalama $\Delta \mathrm{E}$ değerleri karşılaştırıldığında ise renklendirme işleminden sonra istatistiksel olarak anlamlı renklenme tespit edilmiştir $(p \leq 0,05)$. RNC
(Lava Ultimate; 3M ESPE) numunelere göre nanohibrit kompozit (Grandio/Voco) numunelerde görülen bu kabul edilemez renklenmenin malzemelerin matriks yapısının etkisinden kaynaklandığı düşünülmektedir.

Çok sayıda çalışma, kompozit bazlı materyallerin renklenmesinde rezin matriks yapısının etkisi olduğunu tespit etmiştir. ${ }^{52-54}$ RNC (Lava Ultimate; 3M ESPE) matriks yapısı Bis-GMA (bisfenol A-glisidil metakrilat), TEGDMA (trietilen glikol dimetakrilat), UDMA (üretan dimetakrilat) ve Bis-EMA (ethoxylated bisfenol A dimetakrilat)'dan oluşurken, nano-hibrit kompozit rezinin (Grandio/Voco) matriksi yalnızca BisGMA ve TEGDMA'dan oluşmaktadır.

Bis-GMA monomerinin renklenmesi, yapısındaki $\mathrm{OH}$ grupları sebebiyle su emilim miktarlarının artmasının sonucudur. Nano hibrit kompozit rezinin matriks yapısındaki, Bis-GMA su emilimini \%3-6 arası arttırırken, hidrofilik TEGDMA da $\% 0-1$ oranında su emilimini arttırır. ${ }^{54}$

Buna karşılık RNC (Lava Ultimate; 3M ESPE) matriks yapısında bulunan hidrofobik UDMA, Bis-GMA ile kıyaslandığında düşük su absorpsiyonu ve çözünürlüğü ile renklenmeye karşı daha dirençlidir. ${ }^{11,31} \mathrm{Bu}$ çalışmada neden, nano-hibrit kompozit rezinin (Grandio/Voco) renklenmeye karşı daha dirençsiz olduğunun açıklaması olabilir.

$\mathrm{Bu}$ çalışmanın limiti malzemelerin kimyasal özellikleri ile sınırlı kalmıştır ancak RNC ve kompozit rezinlerin renklenmesine etki eden bir çok faktör vardır bunlar arasında malzemenin yüzey pürüzlülüğü, cilalanma tekniği, su tutma kapasitesi vb. özellikleri sayılabilir. Bu açıdan değerlendirildiğinde ilerideki çalışmalarda bu parametrelerin de değerlendirilmesi gerekliliği vardır.

\section{SONUÇ}

1-Nano-hibrit kompozit rezin (Grandio/VOCO), RNC (Lava Ultimate; 3M ESPE) 'e göre klinik olarak kabul edilemez düzeyde renklenmektedir.

2-24 saatlik ve 72 saatlik beyazlatıcı ağız gargarası içerisinde bekletilmesi sonucunda her iki malzemede de istatistiksel olarak $(\Delta \mathrm{E})$ değerlerinde anlamlı düşüş bulunmuştur. Bu sonuç beyazlatıcı ağız gargarasının Nano-hibrit kompozit rezin (Grandio/ VOCO) ve RNC (Lava Ultimate; 3M ESPE) malzemelerinde etkin bir beyazlatma sağladığını göstermektedir.

NOT: Çalışmada herhangi bir yazar, kurum ya da kuruluş ile çıkar çatışması içerisinde bulunmamaktadır. Makale daha önce hiçbir yerde yayınlanmamış ve yayınlanmak üzere işlem görmemektedir 


\section{KAYNAKLAR}

1. Fasbinder D. Chairside CAD/CAM: an overview of restorative material options. Compend Contin Educ Dent 2012; 50:2-8.

2. Fasbinder DJ. The CEREC system: 25 years of Chairside CAD/CAM Dentistry. J Am Dent Assoc 2010; 141:3-4.

3. Batalha-Silva S, de Andrada MA, Maia HP, Magne $P$. Fatique resistance and crack propensity of large MOD composite resin restorations: Direct versus CAD/CAM inlays. Dent Mater 2013:29:324-31.

4. Peutzfeldt A, Asmussen E. The effect of postcuring on quantity of remaining double bonds, mechanical properties, and in vitro wear of two resin composites. J Dent 2000; 28:447-52.

5. Leinfelder KF. Indirect posterior composite resins. Compend Contin Educ Dent 2005; 26:495-503.

6. Arif $\mathrm{R}$, Yilmaz $B$, Johnston WM. In vitro color stainability and relative translucency of CAD-CAM restorative materials used for laminate veneers and complete crowns. J Prosthet Dent 2019;122:160-6.

7. Giordano R. Materials for chairside CAD/CAMproduced restorations. J Am Dent Assoc 2006; 137(Suppl): 14-21.

8. de Oliveira AL, Botta AC, Campos JA, Garcia PP. Effects of immersion media and repolishing on color stability and superficial morphology of nanofilled composite resin. Microsc Microanal 2014; 20:1234-9.

9. S. Ardu, O. Duc, E. Di Bella, I. Krejci. Color stability of recent composite resins. Odontology 2017; 105:29-35.

10. Barutçugil Ç, Harorlı OT, Seven N. Bazı geleneksel içeceklerin mikrohibrit kompozit rezinde meydana getirdiği renk değişikliklerinin incelenmesi. Atatürk Üniv Diş Hek Fak Derg 2012; 22:2: 114-9.

11. Stawarczyk B, Sener B, Trottmann A, Roos M, Özcan M, HF Hammerle C. Discoloration of manually fabricated resins and industrially fabricated CAD/ CAM blocks versus glass-ceramic: Effect of storage media, duration, and subsequent polishing. Dent Mater J 2012; 31: 377-83.

12. Ergücü Z, Türkün, LS, Aladag A. Color stability of nanocomposites polished with one-step system. Oper Dent 2008; 33: 413-20.

13. Fontes ST, Fernandez MR, Moura CM, Meireles SS. Color stability of a nanofill composite: effect of different immersion media. J Appl Oral Sci 2009; 17:388-91.
14. Madhyastha PS, Naik DG, Kotian R, Srikant N, Bhat KMR. Effect of Staining Solutions on Color Stability of Silorane \& Methacrylate Restorative Material. Int J Biomed Sci 2015;11: 29-34.

15. Yousef M, Abo Elnaga A. Color Stability Of Different Restoratives After Exposure To Coloring Agents. J Am Sci 2012;8: 20-6.

16. Chen $\mathrm{MH}$. Update on dental nanocomposites. J Dent Res 2010; 89:549-60.

17. Erdemir U, Yildiz E, Eren MM. Effects of sports drinks on color stability of nanofilled and microhybrid composites after long-term immersion. J Dent 2012;40 Suppl 2: e55-63.

18. Gönülol N, Yilmaz F. The effects of finishing and polishing techniques on surface roughness and color stability of nanocomposites. J Dent 2012;40 Suppl 2: 64-70.

19. Kurt M, Turhan Bal B, Bal C. Güncel Renk Ölçüm Yöntemleri: Sistematik Derleme. Turkiye Klinikleri J Dental Sci 2016;22:130-46.

20. Brewer JD, Wee A, Seghi R. Advances in color matching. Dent Clin North Am 2004;48:341-58.

21. Ragain, Jr, JC. Johnston WM. Color Acceptance of Direct Dental Restorative Materials by Human Observers. Color Res Appl 2000; 25: 278-85.

22. Chu FC, Chow TW, Chai J. Contrast ratios and masking ability of three types of ceramic veneers. J Prosthet Dent 2007; 98:359-64.

23. Celik G, Uludag B, Usumez A, Sahin V, Ozturk O, Goktug G. The effect of repeated firings on the color of an all-ceramic system with two different veneering porcelain shades. J Prosthet Dent 2008; 99:203-8.

24. O'Brien WJ, Hemmendinger $\mathrm{H}$, Boenke KM, Linger JB, Groh CL. Color distribution of three regions of extracted human teeth. Dent Mater 1997;13: 17985.

25. Harorlı OT, Barutçugil Ç. Color Recovery Effect of Commercial Mouth Rinses on a Discolored Composite, J Esthet Restor Dent 2014; 26:256-63.

26. Yu H, Li Q, Cheng H, Wang Y. The effects of temperature and bleaching gels on the properties of tooth-colored restorative materials. J Prosthet Dent 2011;105:100-7.

27. Keshvad A, Hooshmand T, Asefzadeh F, et al. Marginal gap, internal fit, and fracture load of leucite-reinforced ceramic inlays fabricated by Cerec in lab and hot-pressed techniques. J Prosthodont 2011; 20:535-40.

28. Yu B, Lee YK. Difference in opalescence of restorative materials by the illuminant. Dent Mater 
2009; 25:1014-21.

29. Borges ALS, Costa AKF, Saavedra GSFA, Komori $P C P$, Borges $A B$, Rode $S M$. Color stability of composites: effect of immersion media. Acta Odontol Latinoam 2011; 24: 193-9.

30. Habib AN, Abdelmoniem SA, Mahmoud SA. Effect of children's drinks on color stability of different dental composites. An in vitro study. J Clin Pediatr Dent 2017;41:120-5.

31. Ertas E, Guler AU, Yucel AC, Koprulu H, Guler E. Color stability of resin composites after immersion in different drinks. Dent Mater J 2006; 25: 371-6.

32. Alberton Da Silva V, Alberton Da Silva S, Pecho OE, Bacchi A. Influence of composite type and light irradiance on color stability after immersion in different beverages. J Esthet Restor Dent. 2018; 30: $390-6$.

33. Ferracane JL, Condon JR. Rate of elution of leachable components from composite. Dent Mater 1990; 6:282-7.

34. Gürdal, P, Akdeniz BG, Hakan, Sen B. The effects of mouth rinses on microhardness and colour. J Oral Rehabil 2002; 29: 895-901.

35. Chu SJ, Devigus A, Mieleszko A. Fundamentals of Color: Shade Matching and Communication in Esthetic Dentistry. Chicago: Quintessence Publishing; 2004. p. 14-85.

36. Brook AH, Smith RN, Lath DJ. The clinical measurement of tooth Color and stain. Int Dent J 2007; 57: 324-30.

37. Dogan A, Yuzugullu B. Renk seçiminde güncel teknolojik gelimeler. Atatürk Üniv Diş Hek Fak Derg 2011; Supp 4: 65-73.

38. Okubo SR, Kanawati A, Richards MW, Childress S. Evaluation of visual and instrument shade matching. J Prosthet Dent 1998;80:642-8.

39. Johnston WM, Kao EC. Assessment of appearance match by visual observation and clinical colorimetry. J Dent Res 1989; 68:819-22.

40. Judeh A, Al-Wahadni A. A comparison between conventional visual and spectrophotometric methods for shade selection. Quintessence Int 2009;40:e69-79.

41. Bahannan SA. Shade matching quality among dental students using visual and instrumental methods. J Dent 2014; 42:48-52.

42. Paul S, Peter A, Pietrobon N, Hämmerle $\mathrm{CH}$. Visual and spectrophotometric shade analysis of human teeth. J Dent Rest 2002; 81:578- 82.

43. Yannikakis SA, Zissis AJ, Polyzois GL, Caroni C. Colour stability of provisional resin restorative materials. J Prosthet Dent. 1998; 80: 533-9.

44. Ruyter IE, Niler K, Moller B. Color stability of dental composite resin materials for crown and bridge veneers. Dent Mater 1987; 3:246-51.

45. 'Brien WJ, Groh CL, Boenke KM. A new, smallcolor-difference equation for dental shades. J Dent Res 1990; 69:1762-4.

46. Khokhar ZA, Razzoog ME, Yaman P. Colour stability of restorative resins. Quintessence Int 1991; 22: 733-7.

47. Um CM, Ruyter IM. Staining of resin-based veneering materials with coffee and tea. Quintessence Int 1991; 22:377-86.

48. Dogheim AY, El Kady AS, Ghoneim MM, Maha A. Abdelmotie MA. In vitro comparative study of Lava Ultımate CAD/CAM restorative system in comparison to IPS E-max Press. Alexandria Dental Journal. 2016; 41:156-62.

49. Domingos PA, Garcia PP, Oliveira AL, Palma-Dibb RG. Composite resin color stability: influence of light sources and immersion media. J Appl Oral Sci. 2011;19:204-11.

50. Sabatini C. Color stability behavior of methacrylate-based resin composites polymerized with light-emitting diodes and quartz-tungstenhalogen. Oper Dent. 2015; 40:271-81.

51. Fortin D, Vargas MA. The spectrum of composites: new techniques and materials. J Am Dent Assoc, 2000; 131(Suppl):26-30.

52. Janda R, Roulet JF, Kaminsky M, Steffin G, Latta M. Color stability of resin matrix restorative materials as a function of the method of light activation. Eur J Oral Sci 2004; 112: 280-5.

53. Turkun LS, Turkun M. Effect of bleaching and repolishing procedures on coffee and tea stain removal from three anterior composite veneering materials. J Esthet Restor Dent 2004; 16: 290-301.

54. Bagheri R, Burrow MF, Tyas M. Influence of foodsimulating solutions and surface finish on susceptibility to staining of aesthetic restorative materials. J Dent 2005; 33: 389-98.

\section{Yazışma Adresi}

Dr. Dt. Işıl Damla ŞENER YAMANER

DMR DENT Ağız ve Diş Sağlığı Polikliniği

Levent Mah. Levent Cad.

Beşiktaş-İstanbul

Phone no: 02122703066

Fax no: 02122703068

e-mail: isildamlasener@gmail.com 